\title{
Independencia sin insurgentes. El bicentenario y la historiografía de nuestros días*
}

\section{Luis Fernando Granados}

\begin{abstract}
Este artículo busca, por una parte, caracterizar la historiografía actual sobre las guerras "mexicanas" de independencia —en particular la llamada nueva historia política-. Por la otra, aspira a vincular esa historiografía con el clima social y político en el que tuvo lugar la conmemoración del bicentenario. En conjunto, el ensayo advierte el eclipse de la insurgencia popular del paisaje historiográfico contemporáneo y sugiere que todavía hay algo importante que decir acerca de ella, lo mismo por razones historiográficas que políticas.
\end{abstract}

PALABRAS CLAVE: bicentenario, independencia, historiografía, "pueblo"

\section{Independence without Insurgents. Bicentenary and Historiography of OurTimes}

This article seeks, on the one hand, to characterize the current historiography on the "Mexican" wars for independence -in particular, the so-called new political history. On the other, it aims to link such historiography to the social and political climate in which the bicentennial celebrations took place. Overall, the essay notices the eclipse of popular insurgents from the historiographical landscape, and suggests that there is still something relevant to be said about them -both in historiographical and political terms.

KEYWORDS: bicentenary, independence, historiography, "people”

Luis Fernando Granados: Center for Latin American Studies, University of Pennsylvania, Estados Unidos luisfernandogranados@me.com

Desacatos, núm. 34, septiembre-diciembre 2010, pp. 11-26

Recepción: 27 de octubre de 2009 / Aceptación: 16 de enero de 2010

* Casi todo lo que aquí se dice nació de largas conversaciones con Mario Vázquez Olivera. En octubre de 2008, a instancias de Emilio Kouri, expuse el carozo de este ensayo en el seminario del Katz Center for Mexican Studies de la University of Chicago. El impulso para ponerlo por escrito provino de Marcela Dávalos y Fabrizio Mejía Madrid, mientras que Daniela Spenser me indujo a darle su forma final. Mauricio Tenorio Trillo, Tomás Granados Salinas y los dictaminadores y correctores de Desacatos, por su parte, consiguieron enmendar algunos desatinos.

: Alejandro Herrera Dublán, por último, me puso sobre la pista de un par de hechos dignos de mención. A todos, naturalmente, les agradezco su $\dot{\dot{\partial}}$ ayuda, y me disculpo por cualquier "préstamo involuntario" que hayan padecido. 
A 1 final, por supuesto, nadie resultó sorprendido: las celebraciones del bicentenario de la Independencia carecieron de estatura y donaire; más aún, fueron cursis, convencionales y caras. Aunque hubo muchas reuniones académicas, las referencias a la Independencia en el discurso político alcanzaron niveles insospechados, y mucha gente se interesó genuinamente por recordar lo ocurrido en 1810, puede decirse que muy poco de lo acontecido en 2010, celebratoriamente hablando, sobrevivirá a la desmemoria navideña. La causa inmediata de esta situación es conocida: después de tantos cambios de rumbo y personal, pero sobre todo dada la medianía de quien se encargó de coordinar los festejos durante casi dos años, es claro que muy poco de lo organizado por el gobierno federal podrá ser digno de aplauso. El modo en que José Manuel Villalpando fue derrocado — como resultado de una intriga palaciega precipitada por su altanería — no fue sino una evidencia más de la improvisación burocrática generalizada ${ }^{1}$.

Es imposible, sin embargo, responsabilizar a una sola persona - $\mathrm{O}$ a un grupo de funcionarios - de lo ocurrido. Como Miguel Ángel Granados Chapa, Lorenzo Meyer y Humberto Musacchio, entre otros, señalaron desde hace mucho tiempo, es más significativo el hecho de que ese conjunto de falsos inicios, querellas personales, ten-

\footnotetext{
${ }^{1}$ Aunque ha escrito una veintena de libros de historia —incluida una trilogía de "memorias": del virrey Calleja, de la mujer del virrey Gálvez y de Maximiliano de Habsburgo—- José Manuel Villalpando no es de ninguna manera un historiador profesional. Abogado de la Escuela Libre de Derecho, donde más tarde fue profesor de "historia del derecho patrio" (sic), se ha dedicado a la difusión de la historia antes que a la investigación o la docencia, primero como guionista de telenovelas — señaladamente La antorcha encendida - y más tarde como "coordinador académico" de la editorial Clío y comentarista en el noticiero radiofónico Monitor. En junio de 2007 fue nombrado director general del Instituto Nacional de Estudios Históricos de las Revoluciones de México (INEHRM). Un año y medio más tarde, en octubre de 2008, el gobierno federal decidió que el INEHRM sería la dependencia encargada de "coordinar" los festejos de ambos centenarios, tras la renuncia de Rafael Tovar y de Teresa. El 11 de julio de 2010, el diario Reforma publicó una entrevista en la que Villalpando acusó a sus críticos de ser no más que "envidiosos" y defendió con arrogancia las acciones que coordinaba, pero cuyos detalles no pudo aclarar; véase Ricardo, 2010. Diez días después, el secretario de Educación Pública, Alonso Lujambio, anunció que su oficina sería la cabeza del esfuerzo gubernamental, y también su única voz autorizada; sin destituirlo, lo despojó del control de los festejos.
}

taciones monetarias y cursilería intelectual reflejara el carácter del nuevo régimen en relación —en su relación- con la estructura histórica e historiográfica del país. En otras palabras: éste y el anterior gobierno federal se encontraban en una situación incómoda respecto de los "héroes que nos dieron patria", porque ambos son herederos de quienes, al menos desde el cuarto decenio del siglo pasado, se opusieron al proyecto ideológico-institucional de la Revolución Mexicana y, en consecuencia, no podían asumir la versión del pasado que durante décadas sustentó al nacionalismo revolucionario del $\mathrm{PRI}^{2}$. Para explicar lo ocurrido con las conmemoraciones oficiales desde el nombramiento de Cuauhtémoc Cárdenas no hizo falta invocar la nacionalidad del finado Juan Camilo Mouriño o la afinidad del partido gubernamental con José María Aznar. El problema era más bien que los herederos ideológicos de Lucas Alamán no estaban en condiciones de celebrar un estallido revolucionario como el que horrorizó al historiador y político guanajuatense hace dos siglos.

Esa ambigüedad ideológica es fundamental para entender la mediocridad que envolvió los festejos. Incapaz - y sin ganas - de romper con el pasado priista, el nuevo régimen imaginó un vasto pero incoherente espectáculo en el que se desplegaron casi todos los tropos de la "historia oficial" pero muy pocas de sus convicciones. Se hicieron circular monedas conmemorativas con los rostros de personajes enteramente convencionales, pero algunas de las figuras principales de la Revolución (Emiliano Zapata, por ejemplo) se demoraron en aparecer de manera casi sospechosa. Durante más de un año se financió — subcontratándola, no por nada se trata de un régimen neoliberal- la edición de una revista de lujo en la que las grandes eminencias de la historiografía desplegaron su erudición sin sentirse obligadas a vincular el pasado con el presente (es cierto que se dedicó un espacio para tal ejercicio, pero las mesas redondas del ciclo "Discutamos [a] México" se destacaron menos por la agudeza de sus protagonistas que por cierta ansiedad antihistórica, como si el futuro del país dependiera del

\footnotetext{
2 Entre otros muchos comentarios, véanse por ejemplo Granados Chapa, 2007, Musacchio, 2009, y Meyer, 2010.
} 
exorcismo de sus "traumas históricos"). En los portales internéticos, mientras tanto, el gobierno se empeñó en reducir los procesos sociales a meras listas de efemérides y datos "curiosos" - aunque, por otra parte, es más que plausible la publicación en línea de viejos periódicos y libros acerca de ambas gestas-. Por aquí y por allá se realizaron festivales y actos cívicos para enaltecer el nombre de México en el mundo, como corresponde a una clase política cuyo objetivo último es construir un "país ganador". Se construyó también un fastuoso diorama a las afueras de Silao, que por desgracia será recordado más por el dispendio presupuestal que lo acompañó que por las presuntas innovaciones museográficas que contiene. Y si bien es indudable que algunas de las obras de teatro comisionadas para la ocasión sobrevivirán a la coyuntura, la televisación de los festejos - o sea, su conversión en ostentosos melodramas cubiertos por toneladas de miel— no parece haber sido el modo más apropiado para evocar momentos históricos más bien caracterizados por la rabia, la violencia, el desorden y los delirios utópicos. (Cuando el principal consorcio televisivo del país se ocupó del asunto, lo hizo de modo tan acartonado que la mayoría de sus viñetas resultaron de hecho idénticas a las estampitas que antaño compraban los escolares con motivo de las fechas patrias, al punto que en el capítulo dedicado al inicio de la insurrección de 1810 pudo oírse decir a Miguel Hidalgo, con toda seriedad - e ignorando el sentido contemporáneo de ciertas palabras-, "somos perdidos, señores; no queda más remedio que ir a coger gachupines".) Finalmente, dado el modo en que fueron tratados los huesos de los héroes en su tránsito de la Columna de la Independencia al Museo Nacional de Historia —esto es, como si fueran reliquias dignas de veneración fetichista—, era claro que en la gran exposición del Palacio Nacional no habría nada que el antiguo régimen no hubiera podido concebir hace medio siglo.

Con todo, hay por lo menos otra circunstancia que puede ayudar a comprender por qué nadie ha sabido, bien a bien, qué hacer con el aniversario de la insurrección "encabezada" por Miguel Hidalgo. Aunque es un fenómeno historiográfico y por ello hasta cierto punto

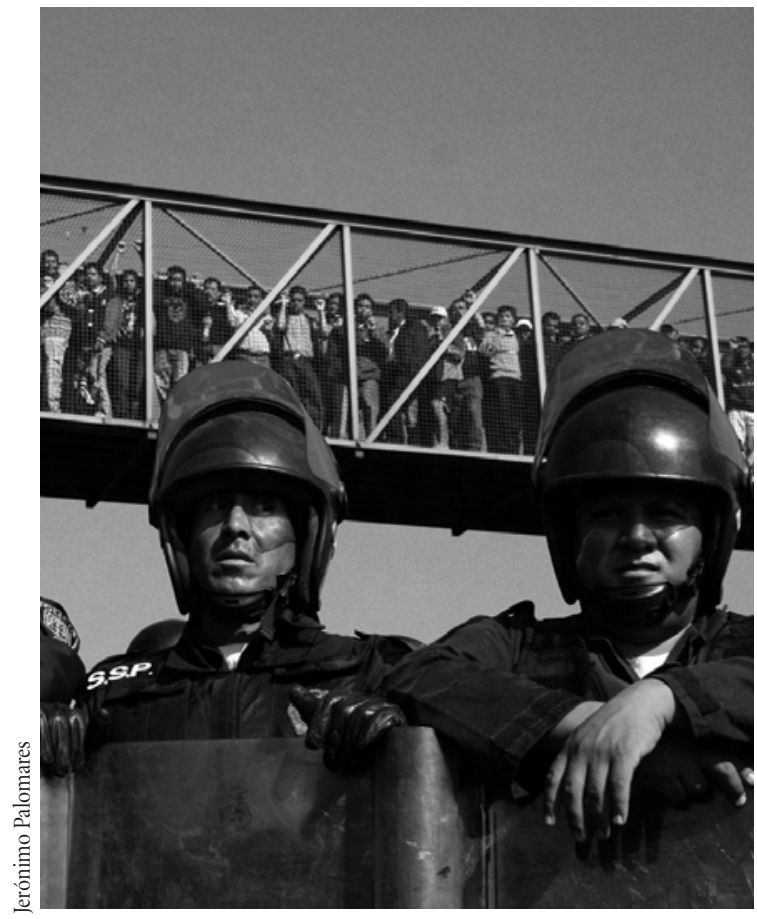

Estado de tiempo, 2007.

parte de la historia interna de la disciplina, es indudable que también es un hecho político y por tanto merece ser estudiado "desde afuera", como un aspecto más de la circunstancia cultural e ideológica por la que atraviesan el país y buena parte del mundo occidental. El propósito de estas páginas es precisamente señalar los rasgos principales del actual momento historiográfico, así como sugerir algunos de los vínculos entre éste y la coyuntura presente. Lo que sigue, por tanto, no aspira a ser un estudio historiográfico propiamente dicho, sino apenas el esbozo de un perfil sociológico de la historiografía contemporánea que acaso sirva para explicar la manera en que los historiadores profesionales han contribuido al clima de incertidumbre que ha rodeado a las celebraciones. En otras palabras, este ensayo se propone mostrar cómo, ineptitud gubernamental aparte, la "crisis" celebratoria tiene que ver con lo que sabemos sobre la guerra de Independencia y la desaparición de Nueva España; que lo que está en crisis es la naturaleza misma de lo que comenzó a ocurrir en septiembre de 1810. 


\section{EL PUEBLOY LOS HÉROES QUE NOS DIERON PATRIA, DE ZÁRATE A LEMOINE}

Hasta hace unos 40 años, lo que algunos llaman el relato maestro de la época de la Independencia —o la historia de bronce, para usar una vieja metáfora de Luis González y González- era un cuento más bien melodramático que describía los actos de un "pueblo" que, como un solo hombre, se liberó de la opresión colonial luego de alcanzar su madurez como entidad colectiva. El "pueblo" mexicano, en esta perspectiva, era la reunión de todos los nacidos y aquellos por nacer en el territorio de Nueva España, que había cobrado conciencia de sí mismo en algún momento entre mediados del siglo XVII y finales del XVIII. Cuando Napoleón Bonaparte se apoderó del trono español en 1808, el "pueblo" mexicano decidió aprovechar la oportunidad para recobrar la soberanía que Hernán Cortés había secuestrado en 1521, poco antes de quemarle los pies a Cuauhtémoc. Y lo hizo con líderes de la talla de Miguel Hidalgo y José María Morelos, que entendieron mejor que nadie que el momento de la indecircunstancias internacionales, la extraña manera en que se "consumó" la Independencia, eran todos aspectos meramente accesorios que apenas merecían una mención al paso.

Este cuento, que ahora sabemos tiene poco que ver con la realidad, comenzó a componerse a fines del siglo XIX mediante una serie de ejercicios pedagógicos que vulgarizaron el planteamiento liberal y nacionalista que fue construyéndose casi desde el momento mismo de la Independencia y que en cierto modo alcanzó su apoteosis en el tercer volumen de México a través de los siglos, el gran monumento historiográfico del liberalismo victorioso (sin embargo, cualquiera que lea el libro de Julio Zárate advertirá muy pronto el abismo entre la simplicidad del relato maestro y la riqueza analítica, aunque también la prosa espesa, del historiador veracruzano) (Rivapalacio, 1888). En el siglo XX, los gobiernos posrevolucionarios se apropiaron de este relato y lo convirtieron en "antecedente" de otra gesta, la de 1910, cuyos presupuestos eran más o menos los mismos. Según esto, también a principios del siglo Xx hubo un "pueblo" unido y un puñado

de líderes inspirados que se puso al frente de las "masas" para acabar con la opresión dictatorial de Porfirio Díaz. El resultado de ambos ciclos de luchas se manifestó con toda claridad en la Constitución de 1917 y, como quien no quiere la cosa, también en los gobiernos priistas.

Además de presumir la existencia del "pueblo" y del vínculo orgánico entre éste y sus dirigentes, el relato maestro daba por sentado el carácter revolucionario de ambos ciclos de movilización popular, en el mismo sentido en que entonces se concebían las "revoluciones" francesa, estadounidense, china o rusa: como una transformación radical de la sociedad, incluso si se reconocía que los cambios fueron sobre todo políticos y culturales y no una mudanza tal que la desigualdad, la pobreza o las clases sociales hubieran desaparecido. La noción de ruptura y por ello la sensación de que el conjunto de la población había tenido que reinventarse de manera profunda eran, así, piezas centrales del relato maestro; y puede que la efectividad política de éste dependiera en última instancia de la inducida impresión — derivada del tropo rupturista - de vivir en el mejor de los mundos posibles. De más está decir que éste es el cuento que todos los nacidos o educados en México aprendimos en la escuela. Y también que es lo que explica el exceso de calles Hidalgo y Morelos, los retratos de los héroes en los billetes, las fechas feriadas en el calendario oficial y casi todo lo que en nuestros días pasa por "esencia" de lo mexicano — con excepción de las pirámides, los mariachis y la Virgen de Guadalupe, naturalmente.

El relato maestro siempre fue disputado, por buenos y malos motivos. Entre los historiadores, habitualmente más tímidos y casi siempre preocupados por las generalizaciones de la mitología estatal, el relato maestro tuvo menos simpatizantes que entre los funcionarios públicos, pero es justo reconocer que su parte medular también caló hondo y definió en buena medida la agenda científica de la historia mexicana en los primeros decenios del siglo XX. Ni los historiadores radicales de la primera mitad del siglo, como Alfonso Teja Zabre y Luis Chávez Orozco, pudieron sustraerse al tono y a algunas de las premisas del relato (Teja Zabre, 1934, y Chávez Orozco, 1947). Un ejemplo paradójico de su éxito es $E l$ proceso ideológico de la revolución de Independencia, el 
espléndido trabajo de Luis Villoro, que en la década de 1950 examinó de manera crítica el carácter de la revolución de Independencia sin renunciar a la idea de que, efectivamente, lo que había ocurrido en Nueva España durante la segunda década del siglo XIX había sido un movimiento revolucionario cuyo resultado más contundente fue la creación del Estado nacional mexicano (Villoro, [1953] 2002). Y otro tanto puede decirse del trabajo de Alfonso García Ruiz, quien en un ensayo célebre consiguió retratar a Hidalgo como un verdadero revolucionario social (García Ruiz, 1955).

De todas formas, desde mediados del siglo XX algunos estudiosos de la época independentista comenzaron a cuestionar los términos mismos del relato maestro, así como a preguntarse otras cosas sobre la coyuntura revolucionaria. Como la parte más endeble del mito era el matrimonio entre pueblo y gobierno -más endeble y más irritante para quienes experimentaban a diario la distancia entre los gobiernos "revolucionarios" y la situación social y política del "pueblo"-, la crítica se encaminó de modo preferente a desmontar la idea de que la Independencia había sido resultado de la acción popular o, de forma más general, contra la presunción de que los líderes independentistas y las masas hubieran hablado alguna vez el mismo idioma. La consolidación de la sociología académica a mediados de siglo debe haber contribuido a legitimar un lenguaje analítico clasista, incluso más que el marxismo a la manera de Chávez Orozco, que siempre fue un poco cardenista en estas latitudes. En todo caso, con trabajos como los del propio Villoro y más tarde - de manera oblicua- de gente como Francisco López Cámara, el consenso historiográfico fue transformándose hasta dar por sentada una profunda división estamental entre los mineros de Guanajuato, aquellos que quedaron representados en la figura del Pípila, y las ideas autonomistas de, por ejemplo, Ignacio López Rayón y sus compadres los Guadalupes ${ }^{3}$.

Acaso el más conspicuo de estos historiadores aggiornados haya sido Ernesto Lemoine, la gran autoridad

\footnotetext{
${ }^{3}$ El tipo de trabajo en el que estoy pensando es López Cámara, 1967.
}

mexicana sobre la guerra de Independencia en los años sesenta y setenta (el otro gran estudioso de esa generación fue Ernesto de la Torre Villar, aunque mi impresión es que su trabajo como colonialista tuvo más impacto que su obra sobre la Independencia) ${ }^{4}$. En particular sus estudios sobre Morelos, además de por un notable escrúpulo, parecen estar animados por una convicción que, sin dejar de ser patriótica y hasta priista emocionalmente, admitía sin remilgos que los proyectos políticos de los dirigentes revolucionarios no eran un sinónimo exacto de las inquietudes y aspiraciones de esos miles de trabajadores empobrecidos que se volcaron detrás de Hidalgo, Morelos, Matamoros y los muchos comandantes guerrilleros ${ }^{5}$. El genio de Morelos - hubiera podido escribir Lemoine, como antes Villoro había escrito de Hidalgoconsistió en haber interpretado con intuición admirable un sentir que las masas no estaban en condiciones de manifestar porque eran analfabetas y carecían de los recursos discursivos necesarios para articular su pensamiento de forma coherente (o más bien, digo yo, de manera que los letrados de entonces y de hoy comprendieran con claridad). Como para Jesús Reyes Heroles, que poco antes se había revelado como el gran artífice del vínculo entre el liberalismo decimonónico y los gobiernos "de la Revolución” (Reyes Heroles, 1957-1961), la gesta independentista en su conjunto tenía para Lemoine un sentido y un propósito que eran al mismo tiempo política y socialmente revolucionarios, o sea que implicaba y había producido una transformación sustantiva de la realidad nacional y no nada más una mutación "política".

Un problema que ninguno de estos historiadores pudo resolver del todo era que, al contrario que en otros países latinoamericanos, la Independencia de la Nueva España no fue la culminación política ni militar de los acontecimientos del bienio 1808-1810. Al contrario, en el origen del Imperio Mexicano de Agustín de Iturbide había una contradicción flagrante con la idea de que los Estados nacionales eran resultado de una fusión entre republicanismo, liberalismo y deseo de independencia, to-

\footnotetext{
${ }^{4}$ En todo caso, véanse Torre Villar, 1964 y 1966.

${ }^{5}$ Véase Lemoine Villicaña, 1965, así como su magistral trabajo de [1979] 1990. Véanse también Torre Villar, 1964 y 1966.
} 
da vez que los conspiradores de 1820 buscaban evitar el restablecimiento de la Constitución española y, más aún, que entre sus dirigentes había personajes famosos por haber combatido con saña a los insurgentes de 18101815 (Iturbide más que nadie) (Anna, 1990). Mientras que en Venezuela, Colombia o Argentina había una clara continuidad y afinidad entre "liberalismo", republicanismo e independencia — representada mejor que nadie por el pensamiento y la acción político-militar de Simón Bolívar-, la cosa era más compleja en Nueva España dado que los primeros y más importantes insurgentes fueron derrotados por una alianza de liberales y conservadores partidarios de España, y las alianzas de 18201821 tenían como premisa la victoria militar de los realistas 6 . Y si no una victoria pura y simple, sí el hecho de que la guerra estaba en un punto muerto que los beneficiaba en el corto plazo.

En general, para resolver este problema de genealogía, el relato maestro contenía una estratagema a la vez lógica y moral. Por una parte, había sido necesario entender la Independencia ya como un acuerdo entre el pasado y el futuro, que era más o menos como Iturbide había planteado la cosa en 1820-1821, ya como una "traición" de la causa de la verdadera independencia (lo cual no era difícil, dado el papel marginal de Vicente Guerrero en los episodios que llevaron a la declaración de Independencia). Por la otra, la continuidad entre la insurgencia "verdadera" y el Estado nacional era resultado de enlazar hechos de mediados del siglo XIX — la victoria de los liberales en las guerras de Reforma y contra Francia- como evidencia de que independencia, república y Estado liberal eran y serían una y la misma cosa desde el 16 de septiembre de 1810 . No por nada la generación de Benito Juárez estaba convencida de que su papel en la historia mexicana era haber conseguido la "segunda independencia”. Lo de menos es que fuera imposible demostrar una continuidad real entre los hechos de 18101815 y la República Restaurada; proclamar esa relación era indispensable para los liberales que por primera vez podían contar y contarse un cuento a la medida de su

\footnotetext{
${ }^{6}$ Entre la vastísima literatura sobre América Latina, véase por ejem-
} plo Langley, 1996. proyecto nacional. Y así los historiadores liberales de la segunda mitad del siglo XIX y de los primeros decenios del siglo XX decidieron de una vez por todas que el único y verdadero padre de la patria era Hidalgo y no Iturbide.

\section{EL ORDEN FRACTURADO: CAMPESINOS, IDEÓLOGOSY CULTURA POLÍTICA}

Desde fines de la década de 1960 comenzó a formarse una reacción contra este especioso argumento del liberalismo decimonónico, y en general contra dos de los pilares del relato maestro: la unión de pueblo y gobierno y la explicación teleológica de la república liberal. Grosso modo, esta reacción ha discurrido por tres caminos principales. Por un lado, ciertos historiadores cuya "educación sentimental" parece haber sido marcada por la Revolución Cubana y la Guerra de Vietnam —y en menor medida por la consolidación de la historia social británica— se propusieron estudiar a los insurgentes de a pie en sus propios términos, con la intención de precisar las causas sociales de fondo del alboroto de la década de 1810 y de paso con el ánimo de restablecer su albedrío como sujetos históricos. Metodológicamente, todos avanzaron por el camino abierto por François Chevalier, aunque por su talante - socially aware, si puede decirse tal cosa - estuvieron más cercanos a Villoro (Chevalier, 1952) ${ }^{7}$. Otro grupo, que puede imaginarse bajo la égida de Lemoine y De la Torre y por ello todavía influido por el nacionalismo liberal, continuó preguntándose si los insurgentes fueron realmente independentistas y liberales; es decir, por ejemplo, si la invocación de Fernando VII en los primeros años de la guerra civil era "real" o fingida. Y un tercer grupo -inspirado directa o indirectamente por Nettie Lee Benson, quien en los años sesenta compiló un libro sobre el tema-prefirió concentrarse en los orígenes del Estado nacional mexicano y por ende dejó de interesarse en los insurgentes plebeyos derrotados con Mariano Matamoros y Hermenegildo Galeana para más bien ocuparse de quienes de verdad inventaron el nuevo

\footnotetext{
${ }^{7}$ Dado que los principales exponentes de esta corriente no escriben en francés, conviene tener presente que la versión inglesa apareció en 1963 , por cierto que ferozmente editada.
} 


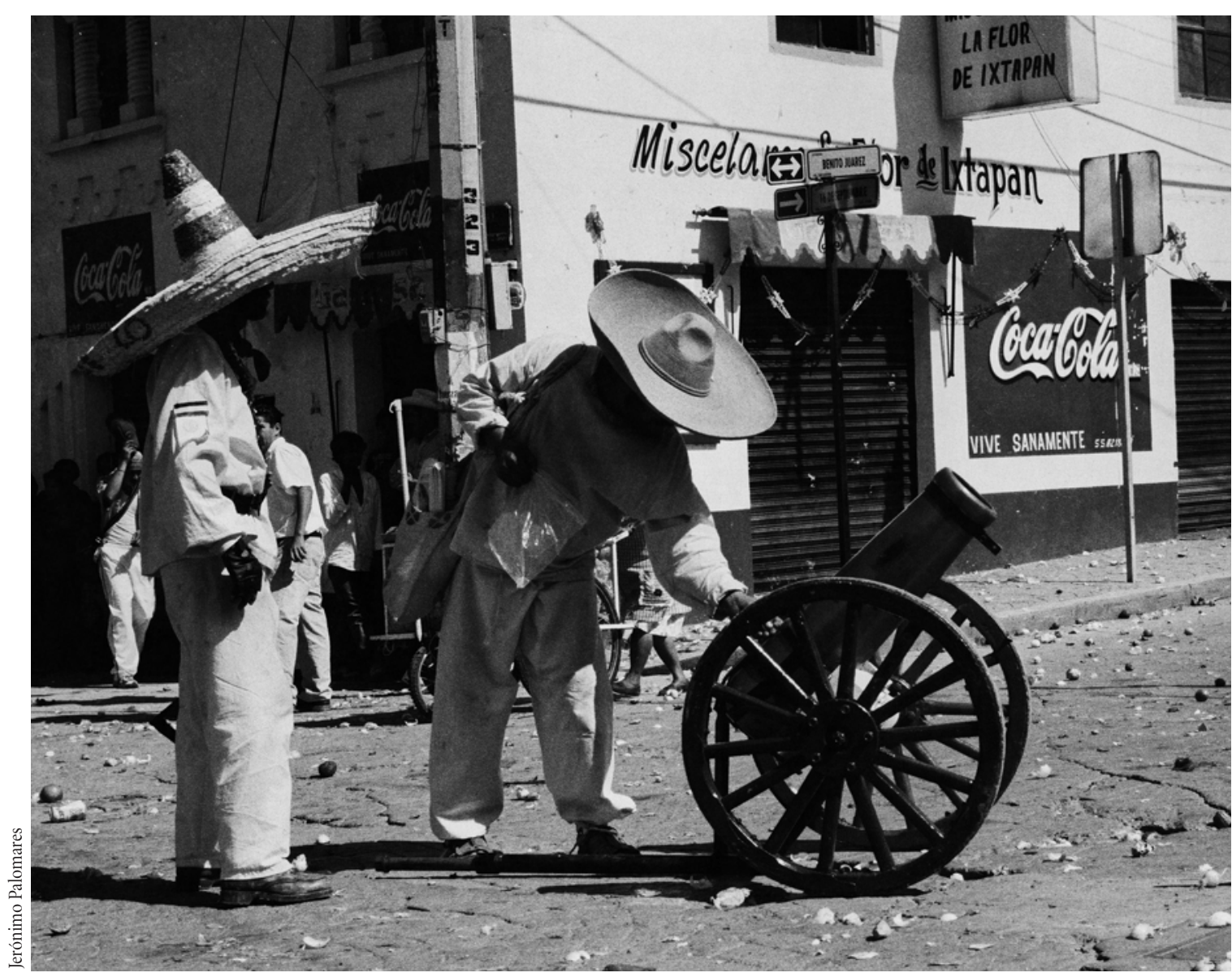

Ixtapan, 2004.

país; esto es, Iturbide, Alamán, Miguel Ramos Arizpe, Lorenzo de Zavala, similares y conexos (Benson,1996).

Este triple embate ha generado resultados formidables desde el punto de vista historiográfico. De los estudios señeros de Enrique Florescano sobre las crisis agrarias del siglo XVIII, los de David Brading sobre la dinámica minero-mercantil del Bajío dieciochesco y los de Claude Morin acerca de la economía michoacana, a los contundentes estudios de Eric Van Young sobre Guadalajara y su hinterland, a los de John Tutino sobre el Bajío y sus alrededores "pacíficos" y los de Brian Hamnett sobre la dimensión regional de la insurgencia, el grupo de historiadores sociales y económicos consiguió demostrar que, por debajo de la agitación política provocada por la crisis dinástica en España, el campo y la minería novohispanos estaban experimentando una verdadera situación revolucionaria en vísperas de 1810 y, más todavía, que la movilización campesina había transformado de manera efectiva las condiciones de vida al menos en el centro del virreinato (Florescano, 1969; Brading, 1971; Morin, 1979; Van Young, 1981; Tutino, 1986; y Hamnett, 1986) (con agudeza casi poética, Tutino tituló un artículo suyo "The Revolution in the Mexican Independence") (Tutino, 1998). En el terreno de la cultura política y militar de los insurgentes, la obra del propio Lemoine fue seguida por trabajos — de altísima calidad — de gente como Virginia Guedea sobre los Guadalupes, Carlos Herrejón sobre la retórica política del periodo, Marco Antonio 
Landavazo sobre el "imaginario monárquico" insurgente y Marta Terán sobre la relación entre indios y conspiradores en Michoacán, gracias a los cuales se volvió inevitable considerar a los líderes insurgentes como actores mucho más sofisticados que los líderes mesiánicos o tradicionalistas de alguna historiografía anterior (Guedea, 1992; Herrejón Peredo, 2003; Landavazo, 2001; Terán, 2002) $)^{8}$.

La tercera vertiente fue la más lenta en desarrollarse, pero se ha convertido casi en hegemónica en los últimos 20 años. Como su ascenso y consolidación han sido contemporáneos de la crisis de los Estados de bienestar y la emergencia del neoliberalismo en el terreno de las ideologías, resulta tentador identificar a estos historiadores con la ola política e intelectual que desde entonces se ha propuesto eliminar las "perversiones" socializantes de la cultura política moderna mediante una definición más restringida —y más decimonónica— del liberalismo. La etiqueta sería sin duda abusiva si se tratara de caracterizar sus preferencias electorales o políticas, pero no se trata de eso: lo que vincula a estos historiadores con los abogados del laissez-faire es su convicción de que la política no puede ser entendida como mero reflejo de los procesos sociales y económicos, sino que debe tenerse como un ámbito fundamentalmente autónomo y capaz de definir lo que los marxistas de antaño llamaban la estructura de la sociedad. Si para el neoliberalismo esto ha implicado renunciar al carácter social y regulador del Estado, para la nueva historiografía — de la Independencia pero también de la Revolución - ha supuesto, aunque parezca contradictorio, interesarse por sobre todas las cosas en el Estado y en la política, con especial atención en sus aspectos discursivos e institucionales.

Nadie como François-Xavier Guerra representa mejor esta corriente historiográfica. Aunque nunca escribió un libro sobre la Independencia (su obra principal sobre el tema es una colección de ensayos por demás brillantes), su influjo entre los historiadores sólo puede ser equiparado al que François Furet ejerció sobre los especialistas de la Revolución Francesa en la década de 1970, y más o

\footnotetext{
${ }^{8}$ Hay que decir que el último es una suerte de who's who de la historiografía reciente sobre la independencia.
}

menos en el mismo sentido: mediante la reivindicación del liberalismo à la Tocqueville en contextos hasta entonces dominados por el romanticismo "populista" à la Michelet (Guerra, 1993) ${ }^{9}$. Junto con Guerra, otros dos estudiosos integran lo que se antoja llamar "la santísima trinidad” del emergente paradigma historiográfico: Antonio Annino y Jaime Rodríguez, quienes por caminos diferentes - al parecer casi antagónicos en el caso del primero- llegaron más o menos al mismo sitio (Annino, 1984 y 1996; Rodríguez O., 1996). Aunque casi nunca obraron de manera coordinada, entre los tres inauguraron un modo de mirar la época que hoy cuenta con practicantes de gran talento y cada vez mayor importancia: Peter Guardino, Juan Ortiz Escamilla, José Antonio Serrano, Alfredo Ávila, Jaime del Arenal, Rafael Rojas, Elías Palti, Roberto Breña y José María Portillo entre los más connotados (Guardino, 1996; Escamilla, 1997; Serrano Ortega, 2001; Ávila, 2002; Arenal, 2002; Rojas, 2003; Palti, 2005; Breña, 2006; y Portillo Valdés, 2006). Completan esta alineación Cristina Gómez y Ana Carolina Ibarra, aunque por el tema de sus investigaciones y su formación profesional quizá haya que considerarlas como un grupo aparte (Gómez Álvarez, 1997, e Ibarra, 2000).

De un modo u otro, todos ellos se han ocupado de rastrear no el vínculo entre insurgencia y Estado nacional sino el origen de la nueva nación independiente desde el punto de vista ideológico, político e institucional. Todos ellos, en consecuencia, han prestado una gran atención a la Constitución de Cádiz de 1812 y al momento gaditano en su conjunto, así como a la relación entre los diferentes grupos sociales novohispanos - funcionarios, militares, campesinos, indios - y la cultura política moderna (tal como ocurre en el ámbito de la Revolución Francesa, empero, el concepto de cultura política ha tendido a señalar la pertenencia a una corriente historiográfica antes que a describir el modo en que una comunidad dada entiende y vive la política). Comprensiblemente, digámoslo de nuevo, porque el liberalismo mexicano nació de esa

\footnotetext{
${ }^{9}$ Para algunos indicios de la posición político-epistemológica de Guerra, véanse las notas necrológicas de Meyer, 2003 y 2004. Una buena introducción a los debates historiográficos relacionados con la Revolución Francesa al tiempo del bicentenario es Kaplan, [1993] 1996, en especial el capítulo sobre Furet, "Vive le Roi".
} 
cumbre de la modernidad católica que fue el primer liberalismo español y no de los anhelos de Hidalgo, Morelos y demás dirigentes rebeldes. En una categoría aparte habría que situar a autores como Timothy Anna y Michael Costeloe, o Hamnett en sus inicios, quienes no aspiraban a estudiar la "cultura política" pero cuya perspectiva acerca del fenómeno independentista —a menudo continental- los llevó a adoptar posiciones análogas al culturalismo, aunque, eso sí, más a tono con lo que casi todo el mundo entiende por política (Anna, 1983; Costeloe, 1986; Hamnett, 1978).

\section{EL REGRESO DEL DISCURSO Y LA DESAPARICIÓN DE LOS REBELDES}

Como puede verse, dos de las tres vertientes en las que se ha desarrollado la historiografía independentista contemporánea pueden calificarse como parte del retorno de la política al proscenio de las ciencias históricas. Se trata ciertamente de una "nueva" historia política, mucho más sensible a las estructuras simbólicas y discursivas que permiten y significan la acción política, si bien no deja de ser revelador que tienda a ocuparse de la materia que, desde tiempo inmemorial, ha sido el principal objeto de atención historiográfica: las palabras de los poquitos que saben escribir y escriben. La historiografía social de la Independencia tiene que verse, en consecuencia, como un intento fallido de reorientar el carácter de los estudios independentistas - fallido porque no consiguió modificar el fondo de la cuestión central planteada por la primera generación de historiadores de la Independencia; es decir, el problema del rompimiento de los vínculos de dependencia entre España y el más antiguo, poblado y próspero de sus virreinatos americanos.

En este sentido La otra rebelión, que es acaso el trabajo de historia social más importante en lo que va del siglo, resulta inquietantemente paradójico: porque no obstante su extensión (1 000 páginas en su edición castellana) y su promisorio subtítulo - Popular Violence, Ideology and the Mexican Struggle for Independence-, el libro más reciente de Eric van Young no tiene casi nada que decir acerca de los ejércitos rebeldes que siguieron a Hi- dalgo y Morelos (Van Young, 2001) ${ }^{10}$. Van Young parece haber intentado una síntesis entre su viejo interés temático (la sociedad de la que salió la insurgencia) y la nueva sensibilidad de quienes se ocupan de la política y el Estado en la primera mitad del siglo XIX. El resultado, empero, es un extraño alegato - complejo, seductor - a favor de la autonomía cultural de los indios insurgentes que niega sin embargo el carácter sociopolítico de su movilización: Van Young ha reconocido que los insurgentes de a pie no buscaban la independencia nacional y ha propuesto en cambio que estaban más bien interesados en restablecer un orden cultural centrado en sus pueblos. Desde su punto de vista, más aún, este esfuerzo de reorganización simbólica y material careció de relación directa con el colapso del imperio español en América; fue más bien como un gigantesco tumulto de esos que estallaban de tanto en tanto en los pueblos novohispanos ${ }^{11}$. Y aunque no es explícito en este punto, me parece que el libro sugiere la profunda irrelevancia de sus muertes y afanes más allá del ámbito pueblerino.

Espero que ahora quede claro por qué creo que el paisaje historiográfico contemporáneo está dominado por una ausencia. Los historiadores de la cultura política insurgente se ocupan ante todo de los proyectos de la dirigencia rebelde, de su profundidad ideológica y las posibilidades frustradas por el infortunio militar. Por su parte, para los nuevos historiadores del Estado mexicano —quienes dominan el escenario actual— la insurrección de 1810 es apenas un prolegómeno, violento, caótico y un tanto sin sentido, del verdadero problema de su quehacer, que es el nacimiento del liberalismo realmente existente (lo que no deja de ser un tanto irónico dado

\footnotetext{
${ }^{10}$ Por ejemplo, de la batalla de Guanajuato sólo encontré menciones en tres momentos, y bastante al vuelo $(6,82,429)$. Y del "ejército" que siguió a Hidalgo hacia el Monte de las Cruces, tengo presente una única referencia (358). En su filoso ensayo a propósito del libro, Knight (2004) alude a esta deficiencia cuando afirma que The Other Rebellion no ofrece una narración general - o un relato maestro- - de la década de 1810 .

${ }^{11}$ En cierto modo, The Other Rebellion puede leerse como una coda del célebre y desconcertante estudio de Taylor (1979), que también minimiza el carácter anticolonial de la "acción directa" de los indios novohispanos y prefiere entenderla como reformista —en el sentido de que no cuestionaba el orden virreinal en tanto que sistema de explotación.
} 


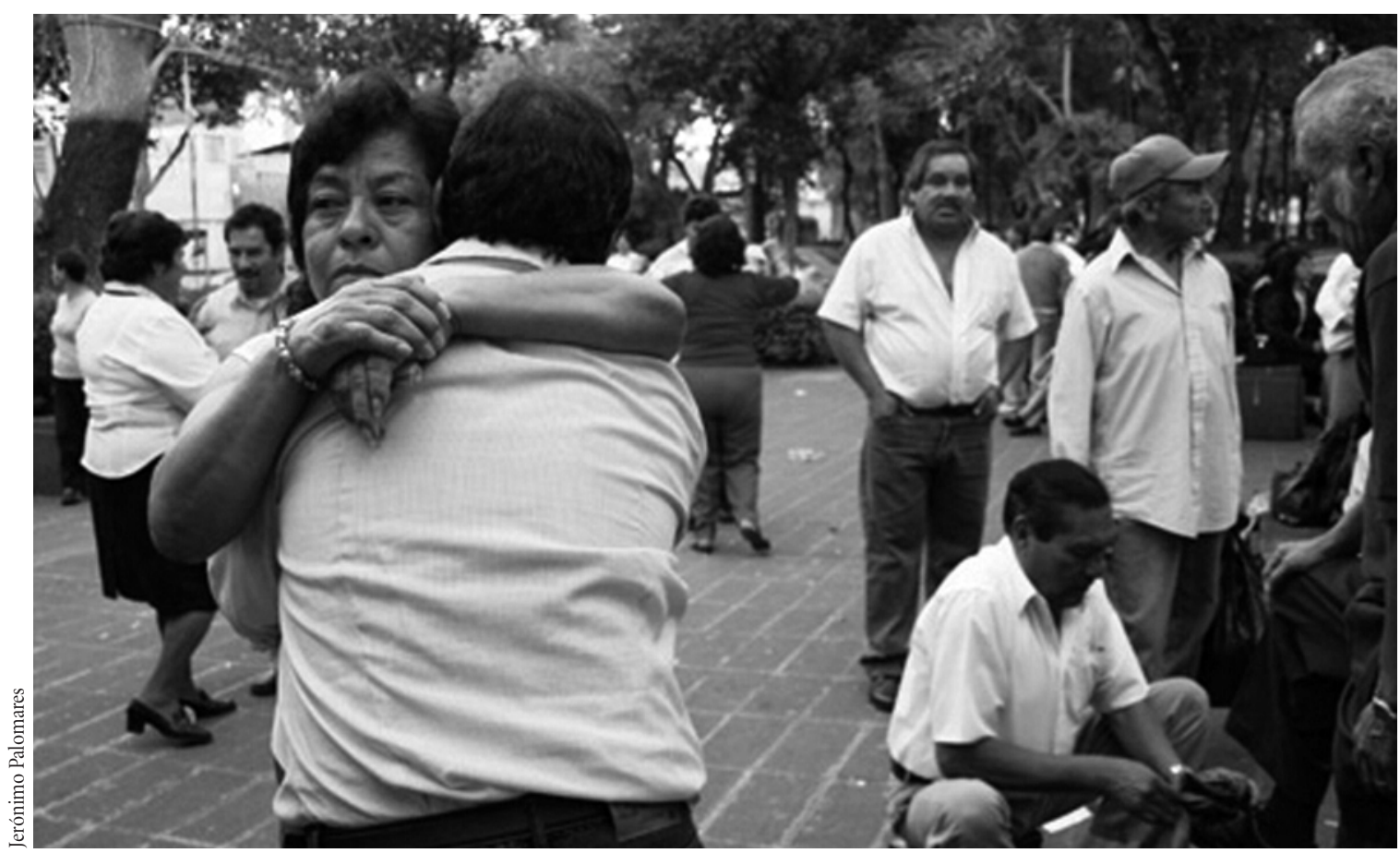

Plaza de la Ciudadela.

que la Constitución de 1812 sólo rigió en las zonas controladas por los realistas y por ello tiene que verse como una ideología contrainsurgente). Y mientras tanto, uno de los estudiosos más perspicaces de la cultura popular novohispana (Van Young) ha concluido que, desde el punto de vista de los rebeldes, un motín de dos días en Atlacomulco, en noviembre de 1810, tuvo más o menos el mismo valor simbólico, y tiene el mismo valor analítico, que la vertiginosa conversión de la original pandilla de Hidalgo en un ejército de por lo menos 20000 personas - esa "turba" que saqueó la capital mundial de la plata en septiembre de ese año, asesinó a buena parte de sus residentes peninsulares e hizo temblar (aunque sólo por un instante) el dominio español en todo el virreinato ${ }^{12}$.

Así las cosas, lo sorprendente del momento actual no son tanto las vacilaciones gubernamentales sino el hecho

\footnotetext{
12 Puesto que Van Young emplea el "motín” de Atlacomulco como arquetipo de la movilización popular en la que está interesado, es hasta cierto punto comprensible que le dedique un capítulo entero. Véase Van Young, 2001, capítulo 15.
}

de que la celebración del año en curso no haya sido cuestionada o puesta en duda de manera general. Después de todo, la orientación de la nueva historiografía sobre las primeras décadas del siglo XIX parece sugerir que por fin ha llegado el momento de remover a la insurgencia de la memoria colectiva y emplear mejor otras metáforas y otras imágenes para representar la Independencia nacional. Efectivamente, en la medida en que la historiografía contribuye a definir la relación entre Estado, pasado y sociedad, resulta un poco absurdo empeñarse en celebrar una rebelión que no tiene nada que ver, ni ideológica ni política ni militarmente, con la independencia del Imperio Mexicano, y que por añadidura estuvo protagonizada por miles de indios, mulatos, mestizos y otras castas, marginados, analfabetas, "tradicionalistas" y, francamente, tan tontos como para creer, durante algunas semanas, que en el carruaje cerrado que acompañaba al "ejército" de Hidalgo viajaba nada más y nada menos que Fernando VII, cuando iban matando a cuanto gachupín encontraban en el camino (gracias a Los pasos de López, esa suculenta 
novela de Jorge Ibargüengoitia, sabemos que en el carruaje viajaban las tres sobrinas muy guapas y muy calladitas del señor cura Periñón) (Ibargüengoitia, 1982).

En otras palabras, atenidos a la tendencia historiográfica reciente, sería un poco más coherente esperar hasta 2012 para celebrar el bicentenario de la Constitución de Cádiz; cambiarle el nombre a los tres fragmentos de la antigua intendencia de México que ostentan los de Guerrero, Hidalgo y Morelos; demoler la estatua real-socialista del Pípila, que tanto afea el paisaje de la ciudad de Guanajuato, o al menos evocar la suerte trágica de Hidalgo "el hombre" — quien a pesar de todas sus lecturas y su innegable don de gentes no pudo nunca contener a esa turba, o conjunto de turbas, que en el curso de cuatro meses hizo volar en pedazos el dominio español en el centro económico del virreinato y más tarde se esfumó para renacer en una miríada de guerrillas invencibles y sin embargo nunca victoriosas_- ${ }^{13}$. O quizá, más aún, convendría concentrar nuestra atención en la prodigiosa inteligencia política de Iturbide, ese criollazo que en unos cuantos meses se las arregló para coaligar viejos insurgentes y guerrilleros de toda índole con la mayor parte del ejército español, los consulados y cabildos principales, la mayor parte de la burocracia y la jerarquía eclesiástica en su conjunto - en suma, los enemigos de diez años de guerra civil más todos los que consiguieron mantenerse al margen del conflicto- - y en una serie de maniobras políticas espectaculares, y casi sin derramamiento de sangre, consiguió la independencia absoluta de Nueva España ${ }^{14}$.

\footnotetext{
${ }^{13}$ Curiosamente, el único intento por replantear radicalmente el relato maestro —o, más bien, el único del que tengo noticia- provino de un ejercicio de difusión: el cuarto episodio de la serie televisiva "Gritos de muert y libertad" (transmitido por primera vez el 2 de septiembre de 2010), en efecto, adoptó el punto de vista del joven Lucas Alamán para describir, y horrorizarse con, la violencia que efectivamente caracterizó la toma de Guanajuato el 28 de septiembre de 1810. Lo interesante de la presentación es que, contrario a la mayoría de los historiadores de antaño, la estampita animada no intentó "justificar" la violencia.

${ }^{14}$ El talento de Iturbide es aún más notable si se tiene presente que el Imperio consiguió además la anexión del reino de Guatemala, o sea las actuales repúblicas de Costa Rica, El Salvador, Guatemala, Honduras y Nicaragua; al respecto, véase Vázquez Olivera, 2010.
}

\section{LOS DESARRAPADOSY EL COLAPSO DEL ORDEN COLONIAL}

Sorprendente o no su silencio, hay que agradecer que la nueva historiografía no haya conseguido influir de manera definitiva en el ánimo conmemorativo del gobierno ni que éste no haya percibido que la nueva historiografía podía ayudarle a reconstruir la mitología del Estado de un modo más acorde con su talante (anticallejero). Agradecer, en efecto, y con todas sus letras, pues el olvido de unos y la negligencia de otros puede ser en realidad una excelente ocasión para revaluar - lo mismo política que historiográficamente - el carácter de esa ola descontrolada de violencia social que tanto se supone que hizo y que ahora parece que no fue nada. A pesar de todas las manipulaciones y todos los resabios románticos que acompañan su evocación, me parece que hay algo en la insurgencia de principios del siglo XIX que la sociedad mexicana de nuestros días merece recordar y aun celebrar ${ }^{15}$.

No es que el relato maestro haya dado en el clavo y que su argumento sea correcto: nadie puede sostener hoy que la nacionalidad mexicana fue la que se puso en marcha el 16 de septiembre de 1810, o que el "pueblo" de México se alzó al unísono para acabar con el despotismo español, o que las multitudes, los ejércitos y las guerrillas rebeldes hayan sido responsables de la independencia nacional. No: el Estado mexicano no es su criatura y por ello no tiene sentido seguir atribuyendo a los insurgentes la paternidad de la patria. Pero, al mismo tiempo, creo que pocos pueden poner en duda que la magnitud de la movilización popular dice mucho acerca de la voluntad de cambio presente en vastos segmentos de la sociedad novohispana, así como de los colosales efectos de sus empeños políticos y militares.

Por una parte, es conveniente recordar que, junto con la revuelta de los esclavos del Santo Domingo francés, la vasta rebelión que sacudió a Nueva España entre 1810 y 1815 fue el movimiento anticolonial más grande en la historia de América. El más grande, en efecto. En sí mis-

\footnotetext{
${ }^{15}$ Para atenuar un tanto la ingenuidad que acaso se perciba en éste y los restantes párrafos, véase Tenorio Trillo, 2009, sobre todo en lo que hace a la independencia del saber histórico popular.
} 


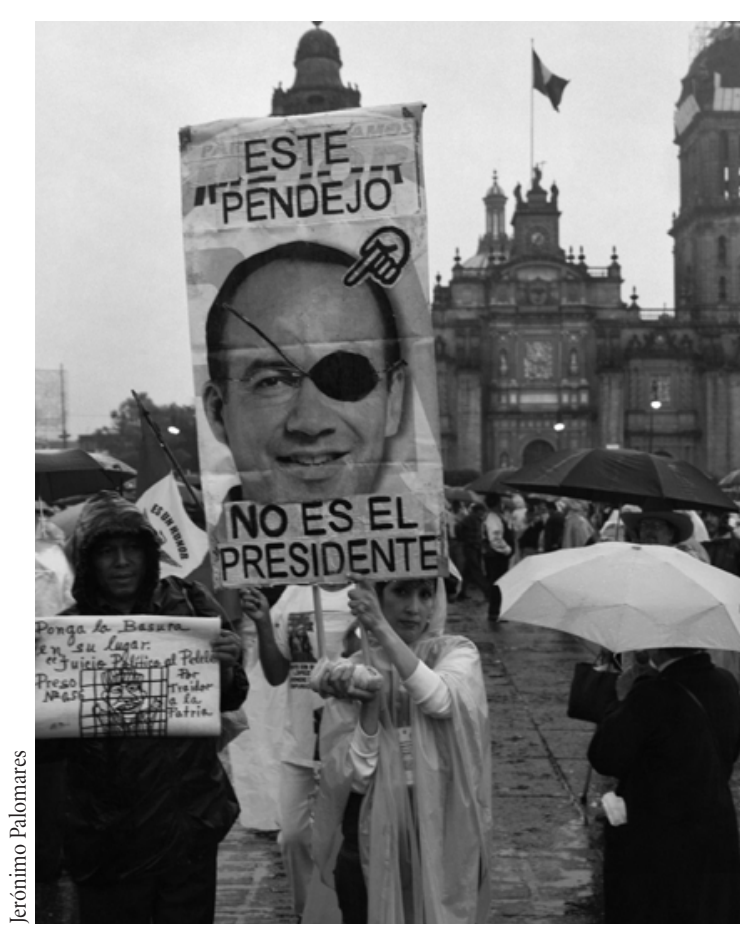

Presidente pirata.

mas, las multitudes reunidas por Hidalgo no tienen parangón en ningún otro lugar del continente, antes o después del colapso imperial de 1808; ese "ejército" fue incluso tanto o más numeroso —y más exitoso— que los contingentes reunidos por Tupac Amaru y Tupac Katari entre 1781 y 1783, que con razón han sido vistos como autores de la rebelión colonial más importante en el imperio español ${ }^{16}$. Y no sólo eso: inspirados directamente por lo que ocurría en el Bajío, pequeños y medianos grupos de rebeldes, y más tarde los ejércitos de Morelos y otros, insurreccionaron buena parte del virreinato con ahínco tal que ni siquiera el fusilamiento de todos los líderes de la primera y segunda hornadas permitió el restablecimiento de la paz social. Este hecho debería ser suficiente para poner en duda la afirmación, que se hace a menudo, de que la Corona de Castilla se mantuvo en posesión de esta porción del mundo casi sin oposición, como si los

\footnotetext{
${ }^{16}$ Para un valioso ejercicio comparativo entre la revuelta novohispana de 1810-1811 y la gran rebelión andina, véase MacFarlane, 1995.
}

indios, mulatos, mestizos y otras castas del virreinato hubieran sido un rebaño de ovejas siempre dispuestas a sacrificarse por los reyes españoles y sus funcionarios o, peor aún, como si no hubieran tenido la capacidad para modelar sus propios destinos - asumidas las restricciones propias de toda vida explotada y subordinada, por supuesto.

En un contexto historiográfico más limitado, el mero tamaño de la insurgencia tendría que obligarnos a repensar uno de los asertos que la nueva historia política hace con frecuencia: esto es, que todo el affaire de la independencia hispanoamericana comenzó en Bayona en mayo de 1808, cuando Napoleón impuso a su hermano como rey de España, y que antes de ese culebrón muy poca gente en el Nuevo Mundo se había atrevido a imaginar un nuevo orden social y político. No afirmo, sin embargo, que los indios, mulatos, mestizos y demás castas que devendrían insurgentes estuvieran pensando en la independencia. Sólo digo que debe suponerse - aunque posiblemente no lo sepamos nunca con exactitud- que muchas personas estaban lo bastante a disgusto con su vida y sus perspectivas futuras como para aventurarse a matar $y$, sobre todo, a morir, luego de que Hidalgo los convocara a "defender" a Fernando VII. Se trata ante todo de un problema de magnitud y de distancias (geográficas y sociales): la respuesta "desde abajo" a los acontecimientos peninsulares fue tan generalizada y tan duradera que explicarla como mero efecto de la decapitación de la monarquía sólo puede hacerse si se cree que el sistema colonial americano era una maquinaria eficiente y bien ensamblada — sospechosamente parecida a la España de la leyenda negra, por cierto-, y no un conjunto heterogéneo de instituciones y prácticas políticas apenas estandarizadas que ejercía su dominio de modos muy distintos y con grandes esfuerzos.

Por otra parte, tampoco hay que olvidar que la insurgencia social inspirada por Hidalgo y una parte de ella encabezada por Morelos, aunque fue derrotada militarmente y no consiguió la independencia de Nueva España, fue responsable de algo incluso más colosal y más importante: casi de un solo tajo, destruyó el principal vínculo económico y financiero que mantenía unido al virreinato con el imperio español y, por extensión, con la 


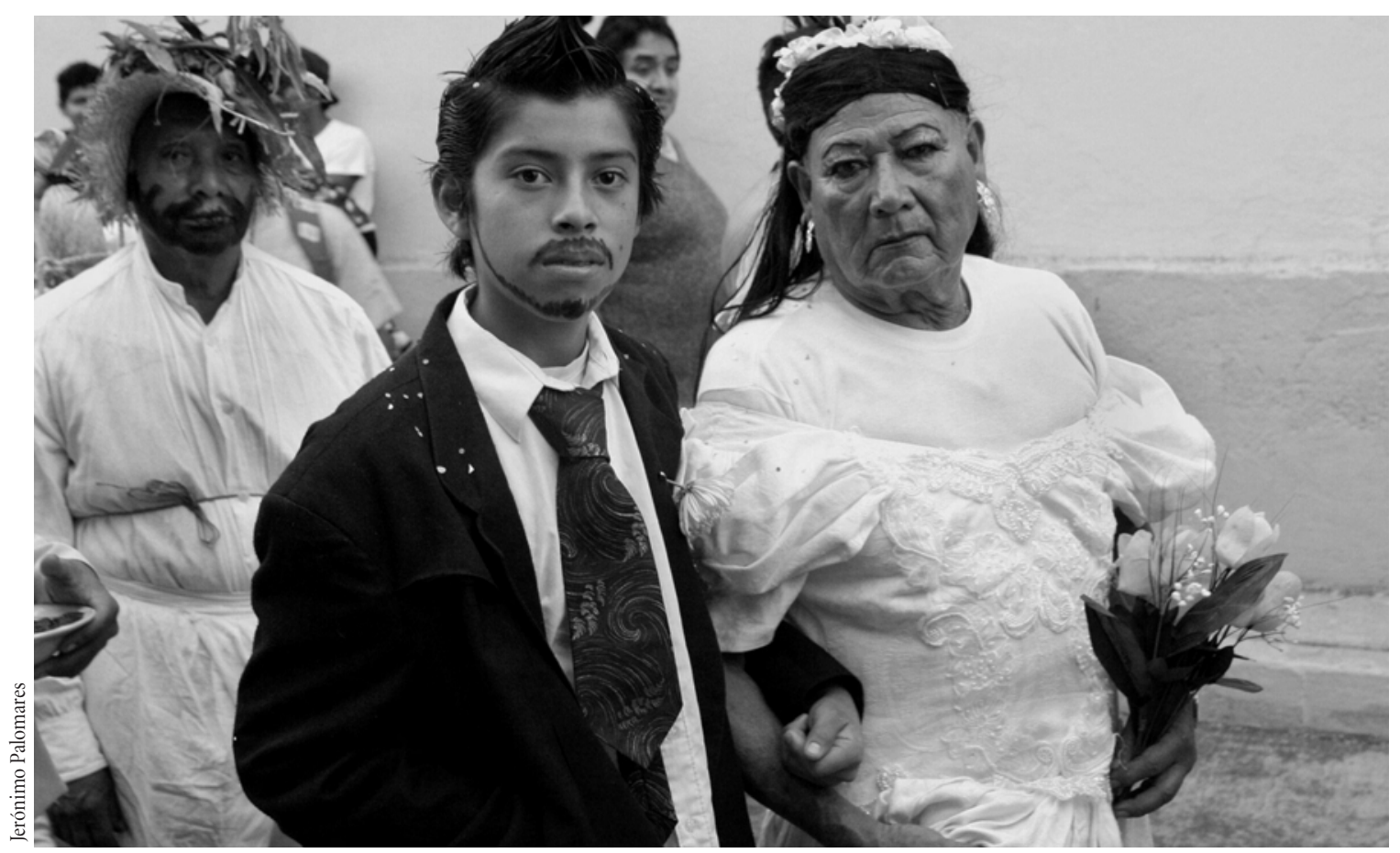

Boda travesti.

economía-mundo europea. Más todavía: la insurgencia no sólo acabó con la producción de plata en el Bajío —que era la zona económicamente más dinámica del virreinato y el motor de la economía española en América del Norte y el Caribe-, sino que reorientó hacia el consumo y los mercados locales un tremendo complejo agrícola y protoindustrial hasta entonces dedicado a alimentar y vestir a los mineros, los dueños de las minas, los funcionarios y todos aquellos cuya vida estaba conectada de algún modo u otro con la producción argentífera (Coatsworth, 1986) ${ }^{17}$. Sin la plata de Guanajuato, que era la piedra de toque del dominio español en Nueva España, el edificio colonial en su conjunto no podía sino venirse abajo. Y eso fue precisamente lo que pasó. La guerra dislocó casi todos los mercados regionales, supu-

\footnotetext{
${ }^{17}$ Para un estudio un poco más reciente sobre la producción de plata en Guanajuato luego de la explosión insurgente, que consigna la crisis de principios de siglo XIX pero se centra en la recuperación de los años cuarenta, véase Rankine, 1992.
}

so un obstáculo a menudo insalvable para el comercio internacional e impidió durante algunos años el enriquecimiento de los grandes productores agrícolas e industriales. Cuando por fin la economía mexicana se reorganizó y se rearticuló a la economía mundial a fines del siglo XIX, lo hizo con más productos provenientes de más regiones; en una palabra, lo hizo de manera un poco más autónoma y diversificada. A riesgo de forzar el lenguaje de los economistas, podría decirse que el efecto macroestructural de la movilización social entre 1810 y 1815 fue fracturar de manera definitiva la dependencia del país de un solo producto (la plata) y promover el mercado interno en buena parte del territorio nacional ${ }^{18}$.

Con todo, ese logro fue un resultado más o menos imprevisto de la guerra social. Los campesinos y mineros que se fueron a la bola con Hidalgo y con Morelos no pensaban en esos términos. Si acaso, pensaban solamen-

\footnotetext{
${ }^{18}$ El argumento original — más claro y mejor fundamentado, ademásse encuentra en Tutino, 1986.
} 
te en función de su propio bienestar, que es como decir el de sus familias y, en cierto modo, el de sus comunidades. Pero es imposible concluir de ello que no estuvieran más o menos al tanto de que acciones similares a las suyas — saquear una hacienda por aquí, matar al tendero gachupín en el pueblo de al lado, juntarse con otros cientos para asaltar Guadalajara o Oaxaca — estaban ocurriendo por todas partes y que en conjunto iban volviendo imposible la normalidad colonial, o sea el orden ideológico e institucional que había prescrito su subordinación y marginación culturales: el orden que se expresaba de manera concreta en la posición privilegiada de quien era a la vez tendero y gachupín, o cura y gachupín, o teniente coronel y gachupín, o administrador de hacienda y gachupín. Con sus actos, si no con sus palabras, esos miles de insurgentes de a pie, humildes, insignificantes, hicieron mucho más por redefinir el paisaje social y cultural de Nueva España que los letrados de toda índole con sus proyectos constitucionales, sus referencias librescas, su sabiduría cosmopolita. Juntos y sin evidente coordinación, como las avalanchas que van haciéndose de piedrita a Hidalgo de Dolores a Guanajuato a Valladolid y a Guadalajara; así auparon a Morelos en sus campañas y sus sentimientos de la nación; así dieron sustento a José Antonio Torres, a Julián Villagrán, a Francisco Xavier Mina $\mathrm{y}$ a todos sus semejantes.

En suma, más que enojarse por la falta de lustre gubernamental a propósito del bicentenario, o deplorar el curso que han tomado los estudios sobre la Independencia en las últimas décadas, creo que es mejor —esto es: más sano y más productivo- aprovechar que el año del bicentenario sigue siendo 2010 para ocuparnos de las insurrecciones hidalgueñas. Después de todo, las rebeliones que comenzaron en septiembre de 1810 fueron obra de gente no muy diferente a los mexicanos de hoy: miles de personas comunes y corrientes, más bien pobres, marginadas, con expectativas de vida poco alentadoras y elocuentes de un modo que parece incomprensible porque hablaban en lenguas indígenas o en el castellano "quebrado" de los pueblos, las minas y las haciendas; que un buen día decidieron arriesgar vidas y bienes -literalmente- por algo tan nimio y concreto como una parce-

la sin renta, un tendero abusivo menos, un funcionario no tan arbitrario, pero que era en realidad algo tan abstracto e "ideológico" como un ajuste de cuentas con el orden colonial y sus principales beneficiarios culturales. Por eso, y aunque la historia no esté para dar clases de civismo, creo que es posible y aun deseable que la sociedad mexicana actual se sirva de las celebraciones de 2010 para pensar una vez más si el propósito de la vida social es dejar que cada quien se rasque con sus propias uñas, o si mejor hacemos algo — lo que sea, pero ideológicamente encarnado como hicieron los insurgentes- antes de que el país termine de desmoronarse.

\section{Bibliografía}

Anna, Timothy E., 1983, Spain and the Loss of America, University of Nebraska Press, Lincoln.

_ 1990, The Mexican Empire of Iturbide, University of Nebraska Press, Lincoln.

Annino, Antonio, 1984, "El pacto y la norma: los orígenes de la legalidad oligárquica en México", Historias, núm. 5, pp. 3-31.

_ 1996, "The Ballot, Land and Sovereignty: Cadiz and the Origins of Mexican Local Government, 1812-1820", en Eduardo Posada-Carbó (comp.), Elections Before Democracy: The History of Elections in Europe and Latin America, Macmillan Press, St. Martin's Press, Hampshire, Basingstoke, pp. 61-86.

Arenal, Jaime del, 2002, Un modo de ser libres: Independencia y Constitución en México (1816-1822), El Colegio de Michoacán, Zamora.

Ávila, Alfredo, 2002, En nombre de la nación: la formación del gobierno representativo en México, 1808-1824, Taurus, Centro de Investigación y Docencia Económicas, México.

Benson, Nettie Lee (comp.), 1966, Mexico and the Spanish Cortes, 1810-1822, Institute of Latin American Studies, University of Texas, Austin.

Brading, David A., 1971, Miners and Merchants in Bourbon Mexico, 1763-1810, Cambridge University Press, Cambridge.

Breña, Roberto, 2006, El primer liberalismo español y los procesos de emancipación de América, 1808-1824: una revisión historiográfica del liberalismo hispánico, El Colegio de México, México.

Chávez Orozco, Luis, 1947, Historia de México, 1808-1836, Patria, México. 
Chevalier, François, 1952, La formation des grands domaines au Mexique: Terre et société aux XVIe-XVIIe siècles, Institut d'Ethnologie, París.

_ 1963 , Land and Society in Colonial Mexico: The Great Hacienda, edición y prólogo de Lesley Byrd Simpson, traducción de Alvin Eustis, University of California Press, Berkeley.

Coatsworth, John H., 1986, "The Mexican Mining Industry in the Eighteenth Century”, en Nils Jacobsen y Hans Jürgen Puhle (comp.), The Economies of Mexico and Peru during the Late Colonial Period, 1760-1810, Colloquium, Berlín, pp. 26-45.

Costeloe, Michael P., 1986, Response to Revolution: Imperial Spain and the Spanish American Revolutions, 1810-1840, Cambridge University Press, Cambridge.

Florescano, Enrique, 1969, Precios del maíz y crisis agrícolas en México, 1709-1810: ensayo sobre el movimiento de los precios y sus consecuencias económicas y sociales, Centro de Estudios Históricos, El Colegio de México, México.

García Ruiz, Alfonso, 1955, Ideario de Hidalgo, prólogo de José Ángel Ceniceros, Secretaría de Educación Pública, México.

Gómez Álvarez, Cristina, 1997, El alto clero poblano y la revolución de Independencia, 1808-1821, Facultad de Filosofía y Letras, Universidad Nacional Autónoma de México, Benemérita Universidad Autónoma de Puebla, México, Puebla.

Granados Chapa, Miguel Ángel, 2007, “Bicentenarios”, Reforma, 21 de agosto.

Guardino, Peter F., 1996, Peasants, Politics, and the Formation of Mexico's National State: Guerrero, 1800-1857, Stanford University Press, Stanford.

Guedea, Virginia, 1992, En busca de un gobierno alterno: los Guadalupes de México, Instituto de Investigaciones Históricas, Universidad Nacional Autónoma de México, México.

Guerra, François-Xavier, 1993, Modernidad e independencias: ensayos sobre las revoluciones hispánicas, Mapfre, Fondo de Cultura Económica, Madrid, México.

Hamnett, Brian R., 1978, Revolución y contrarrevolución en México y el Perú: liberalismo, realeza y separatismo, 18001824, traducción de Roberto Gómez Ciriza, Fondo de Cultura Económica, México.

—, 1986, Roots of Insurgency: Mexican Regions, 1750-1824, Cambridge University Press, Cambridge.

Herrejón Peredo, Carlos, 2003, Del sermón al discurso cívico: México, 1760-1834, El Colegio de México, El Colegio de Michoacán, México.

Ibargüengoitia, Jorge, 1982, Los pasos de López, Océano, México. Ibarra, Ana Carolina, 2000, El cabildo catedral de Antequera, Oaxaca, y el movimiento insurgente, El Colegio de Michoacán, Zamora.

Kaplan, Stephen L., [1993] 1996, Farewell, Revolution: The Historians' Feud, France, 1789-1989, Cornell University Press, Ithaca.
Knight, Alan, 2004, "Eric Van Young, The Other Rebellion y la historiografía mexicana”, Historia Mexicana, vol. 54, núm. 2, pp. 445-515.

Landavazo, Marco Antonio, 2001, La máscara de Fernando VII: discurso e imaginario monárquicos en una época de crisis: Nueva España, 1808-1822, Centro de Estudios Históricos, El Colegio de México, Universidad Michoacana de San Nicolás de Hidalgo, El Colegio de Michoacán, México.

Langley, Lester D., 1996, The Americas in the Age of Revolution, 1750-1850, Yale University Press, New Haven.

Lemoine Villicaña, Ernesto, 1965, Morelos: su vida revolucionaria a través de sus escritos y de otros testimonios de la época, Universidad Nacional Autónoma de México, México.

_, [1979] 1990, Morelos y la revolución de 1810, Facultad de Filosofía y Letras, Universidad Nacional Autónoma de México, México.

López Cámara, Francisco, 1967, La estructura económica y social de México en la época de la Reforma, Siglo XXI Editores, México.

MacFarlane, Anthony, 1995, "Rebellions in Late Colonial Spanish America: A Comparative Perspective”, Bulletin of Latin American Research, vol. 14, núm. 3, pp. 313-338.

Meyer, Jean, 2003, "In memoriam. François-Xavier Guerra", Historia Mexicana, vol. 52, núm. 4, pp. 1131-1133.

__, 2004, "François-Xavier Guerra, 1942-2002", Hispanic American Historical Review, vol. 84, núm. 1, pp. 121-122.

Meyer, Lorenzo, 2010, "La derecha mexicana, incapaz de debatir sobre la historia”, entrevista de Arturo García Hernández, La Jornada, 1 de septiembre.

Morin, Claude, 1979, Michoacán en la Nueva España del siglo XVIII: crecimiento y desigualdad en una economía colonial, traducción de Roberto Gómez Ciriza, Fondo de Cultura Económica, México.

Musacchio, Humberto, 2009, "Siguen los desatinos en el Bicentenario”, Excélsior, 23 de febrero.

Ortiz Escamilla, Juan, 1997, Guerra y gobierno: los pueblos y la independencia de México, Universidad de Sevilla, Sevilla.

Palti, Elías José, 2005, La invención de una legitimidad: razón y retórica en el pensamiento mexicano del siglo XIX (un estudio sobre las formas del discurso político), Fondo de Cultura Económica, México.

Portillo Valdés, José María, 2006, Crisis atlántica: autonomía e independencia en la crisis de la monarquía hispana, Marcial Pons, Madrid.

Rankine, Margaret E., 1992, "The Mexican Mining Industry in the Nineteenth Century with Special Reference to Guanajuato", Bulletin of Latin American Research, vol. 11, núm. 1, pp. 29-48.

Reyes Heroles, Jesús, 1957-1961, El liberalismo mexicano, Facultad de Derecho, Universidad Nacional Autónoma de 
México, México.

Ricardo, Jorge, 2010, "Se aplaude Villalpando por festejo", Reforma, 11 de julio.

Riva Palacio, Vicente (dir.), 1888, México a través de los siglos: historia general y completa del desenvolvimiento social, politico, religioso, militar, artístico, científico y literario de México desde la antigüedad más remota hasta la época actual, vol. 3, La Guerra de Independencia, Espasa-Ballescá, Barcelona, México.

Rodríguez O., Jaime E., 1996, La independencia de la América española, Fondo de Cultura Económica, México.

Rojas, Rafael, 2003, La escritura de la independencia: el surgimiento de la opinión pública en México, Taurus, Centro de Investigación y Docencia Económicas, México.

Serrano Ortega, José Antonio, 2001, Jerarquía territorial y transición política: Guanajuato, 1790-1836, El Colegio de Michoacán, Zamora.

Taylor, William B., 1979, Drinking, Homicide and Rebellion in Colonial Mexican Villages, Stanford University Press, Stanford.

Teja Zabre, Alfonso, 1934, Historia de México: la independencia, Botas, México.

Tenorio Trillo, Mauricio, 2009, “Saber de memoria: 2010 para historiadores”, en Historia y celebración: México y sus centenarios, Tusquets, México, pp. 37-79.

Terán, Marta, 2002, "El movimiento de los indios, las castas y la plebe de Valladolid de Michoacán en el inicio de la Guerra de Independencia, 1809-1810”, en Marta Terán y José Anto- nio Serrano Ortega (comp.), Las guerras de independencia en la América española, El Colegio de Michoacán, Instituto Nacional de Antropología e Historia, Instituto de Investigaciones Históricas, Universidad Michoacana de San Nicolás de Hidalgo, Zamora, pp. 273-294.

Torre Villar, Ernesto de la, 1964, La Constitución de Apatzingán y los creadores del Estado mexicano, Universidad Nacional Autónoma de México, México.

__, 1966, Los Guadalupes y la Independencia de México: con una selección de documentos inéditos, Jus, México.

Tutino, John, 1986, From Insurrection to Revolution in Mexico: Social Basis of Agrarian Violence, 1750-1940, Princeton University Press, Princeton.

-, 1998, "The Revolution in the Mexican Independence: Insurgency and the Renegotiation of Property, Production, and Patriarchy in the Bajío, 1800-1855", Hispanic American Historical Review, vol. 78, núm. 3, pp. 367-418.

Van Young, Eric, 1981, Hacienda and Market in EighteenthCentury Mexico: The Rural Economy of the Guadalajara Region, 1675-1820, University of California Press, Berkeley.

— 2001, The Other Rebellion: Popular Violence, Ideology and the Mexican War for Independence, 1810-1821, Stanford University Press, Stanford.

Vázquez Olivera, Mario, 2010, El Imperio Mexicano y el Reino de Guatemala: proyecto político y campaña militar, 18211823, Fondo de Cultura Económica, Guatemala.

Villoro, Luis, [1953] 2002, El proceso ideológico de la revolución de Independencia, Conaculta, México. 